\title{
BMJ Open Impact of a rural drowning reduction programme in Bangladesh on gender equity, norms and behaviour: a mixed- method analysis
}

\author{
Medhavi Gupta (D) , ${ }^{1}$ Aminur Rahman, ${ }^{2}$ Notan Chandra Dutta, ${ }^{2}$ \\ Md Shafkat Hossain, ${ }^{2}$ Devaki Nambiar, ${ }^{3}$ Samina Parveen, ${ }^{3}$ Rebecca Ivers, ${ }^{4}$ \\ Jagnoor Jagnoor ${ }^{3,4}$
}

To cite: Gupta M, Rahman A, Dutta NC, et al. Impact of a rural drowning reduction programme in Bangladesh on gender equity, norms and behaviour: a mixedmethod analysis. BMJ Open 2020;10:e041065. doi:10.1136/ bmjopen-2020-041065

- Prepublication history and additional material for this paper is available online. To view these files, please visit the journal online (http://dx.doi.org/10. 1136/bmjopen-2020-041065).

Received 01 June 2020 Revised 06 0ctober 2020 Accepted 05 November 2020

Check for updates

(C) Author(s) (or their employer(s)) 2020. Re-use permitted under CC BY-NC. No commercial re-use. See rights and permissions. Published by BMJ.

${ }^{1}$ Injury Division, George Institute for Global Health, Sydney, New South Wales, Australia

${ }^{2}$ Centre for Injury Prevention and Research Bangladesh, Dhaka, Bangladesh

${ }^{3}$ The George Institute for Global Health India, New Delhi, Delhi, India

${ }^{4}$ School of Public Health and Community Medicine, University of New South Wales Faculty of Medicine, Sydney, New South Wales, Australia

Correspondence to

Dr Jagnoor Jagnoor;

jjagnoor1@georgeinstitute.org.in

\section{ABSTRACT}

Objectives Community-based health programmes implemented in low-income and middle-income countries impact community gender norms and roles and relationships, which in turn affect individuals' health outcomes. Programmes should measure their effects on gender norms, roles and relationships in the communities in which they operate to respond to unexpected health consequences. We conducted a gender analysis on a drowning reduction programme in rural Bangladesh to identify its impacts on gendered roles and behaviours in the community.

Design A mixed-method approach was used. Quantitative programme monitoring data were analysed to assess gender differences in participation and engagement. A qualitative approach using interviews, focus group discussions and observations with purposively selected programme implementing staff and participants aimed at finding explanations for quantitative findings and additional impacts of the programme on gender in the community. The analysis was conducted using Family Health International 360's Gender Integration Framework, which identifies both internal (norms) and external (behaviours) effects.

Results Fewer girls $(n=5030)$ participated in swimming classes than boys ( $n=6425$ ) due to cultural restrictions and involvement in domestic work. Women were not hired in leadership roles in the implementing organisation due to lower transportation access and their perceived ability to conduct labour-intensive activities. However, communities become more accepting of local women's mobility and employment due to their engagement as swim instructors. Women swim instructors were more satisfied with the pay and part-time nature of the work as men were able to earn more elsewhere. Menstruation management was ignored as all supervisory staff were men.

Conclusions Systematised strategies are required to ensure equal participation of girls and enable equitable prevention outcomes. Within the implementing organisation, programmatic changes will support gender transformation, such as ensuring women's mobility and engagement in leadership roles. Strategies to combat perceptions that lower paying part time work is more suitable for women than men may be considered.
Strengths and limitations of this study

- We applied both deductive and inductive framework analyses to develop a comprehensive understanding of programme impacts on gender roles and behaviours.

- The mixed-method quantitative and qualitative sample size was large, with low missing data rates.

- We used the Gender Integration Framework to guide the analysis, which identifies both internal (norms and attitudes) and external (roles and behaviours) impacts on gender.

- Some data collection occurred after the end of the programme's delivery season, and respondents may have forgotten their initial experiences.

- We were only able to conduct two observations of SwimSafe classes due to end of season and were not able to reach saturation for this type of data collection.

\section{BACKGROUND}

Community-based health programmes are embedded in their social context and inevitably impact and are impacted by their surrounding environment, including on gender norms, roles and relationships. ${ }^{12}$ Therefore, programmes must consider their effect on gender to ensure that in the pursuit of addressing one health outcome, other harms do not occur. ${ }^{3}$

Gender roles, relationships and perceptions affect individuals' social environment and hence health outcomes. Gender is a key determinant that influences health outcomes through its effect on community perceptions of gender-appropriate behaviours and roles. For example, norms enforcing women's roles as homemakers may reduce their mobility around the community in rural low-income and middle-income country (LMIC) contexts, and therefore access to health information, 
healthcare and resources. Limited mobility also means women are restricted in building social capital in their community, a major determinant of health. ${ }^{45}$ Communities emphasising the role of men as breadwinners limit women's access to employment and decision-making capacity, and men have control over resources coming into the household. Reduced control over resources, poor involvement in decision making and low levels of employment disempower women. ${ }^{6-9}$

Community-based health programmes often employ women, engage a wide range of stakeholders and build close relationships with communities. Because they actively change the roles and behaviours of men and women from traditional norms, these programmes are able to influence gendered attitudes relating to factors such as employment and mobility. These in turn affect health outcomes of individuals, such as by increasing the acceptability of women moving around the community and building social connections, and normalising women's employment. ${ }^{10-13}$

There is a lack of gender-differentiated data and analysis on how health programmes impact gender-based norms, attitudes and behaviours that may in turn impact health outcomes, including of drowning prevention programmes. ${ }^{14} 15$ Programme effects on gender-based differences in mobility privileges, power relationships between community members and expectations on behaviour need to be measured to understand how they influence health outcomes. ${ }^{11}$ For example, previous research has shown that negative perceptions towards women's economic empowerment may lead to higher rates of domestic violence on working women, ${ }^{16}$ but if programmes do not evaluate these outcomes, they will remain invisible. Conversely, greater linkages between women recruited in health programmes and communities often lead to better health information sharing and household well-being. ${ }^{17}$ Techniques such as effective engagement and provision of incentives to support women's employment, mobility and involvement in decision-making have been effective in improving women's autonomy and hence access to healthcare and information for themselves and their families. ${ }^{11} 12$ 18-20

Bangladesh is a lower middle income country with clear gender disparities, with which community-based programmes may interact with. Labour force participation of women is $36 \%$, much lower than men's at $81 \% .^{21}$ Bangladesh ranks 142 out of 167 countries on the Women Peace and Security Index, with low scores on equitable access to education, employment and finances indicators. ${ }^{22}$ In this study, we conducted a gender analysis to identify the relationship between a rural drowning reduction programme in Bangladesh and contextual gender norms, roles and relationships. We aimed to understand programme impacts on gender relationships and related outcomes using the Gender Integration Framework, which provides a comprehensive list of domains on which programmes can have gender impacts. ${ }^{1}$ The detailed protocol for this paper can be found in Gupta et al. ${ }^{23}$ To our knowledge, this is the first gender analysis conducted of a drowning prevent programme. Hence, this paper provides essential insights and guidance to others implementing drowning programmes.

\section{METHODS}

\section{Study setting}

A survey in Bangladesh reported high rates of drowning in 5-9 year old children, at 23 deaths per $100000 .^{24}$ The SwimSafe programme was introduced in 2017 based on the WHO's recommended intervention to train children in swim and rescue skills. ${ }^{25}$ The programme operates across three intervention areas (upazilas) in the Barishal Division in southern Bangladesh: Kalapara, Taltali and Betagi. Children aged 6-10 years old are taught a 21-step survival swimming course over 15 days. Children are considered graduated when they can swim for $25 \mathrm{~m}$, float for $30 \mathrm{~s}$ and perform land-based rescue. Classes run during the summer months from April to September. Classes are provided by trained men $(\mathrm{n}=15)$ and women $(\mathrm{n}=72)$. Community swimming instructors (CSIs) in 65 ponds modified with bamboo structures. Currently, all supervisors are men $(n=6)$, managing 15-20 CSIs each. See online supplemental files 1 and 2 for SwimSafe's organisational chart and logic model.

A wide range of community-level stakeholders are involved in programme delivery and oversight. Each site is overseen by a Village Injury Prevention Committee (VIPC, $\mathrm{n}=171$ ) which comprises parents and other influential community members. Union Injury Prevention Committees (UIPC, $\mathrm{n}=26$ ) have also been set up at government union level (which oversee a population of between 25000 and 50000 people), each with an elected chairman and nine members, one for each administrative ward.

\section{Framework for analysis}

We applied a gender lens to identify benefits and effects of SwimSafe beyond the targeted outcome of reducing drowning. The SwimSafe programme operates in a rural community affected by cultural gender-based norms and roles. Our analysis aimed to understand how SwimSafe impacted gender roles and relationships within communities, especially those with a potential effect on health outcomes. The impacts to participating children, parents, programme staff and other community members were explored.

A mixed-method approach was used in this study. A sequential explanatory design was used where quantitative analysis first identified gender-based differences in participation and outcomes, and qualitative data collection then aimed to explain these. Qualitative analysis also explored additional themes not captured in the programme's routine quantitative data, such as effects on CSIs' independence and changes in gender-related community attitudes. 


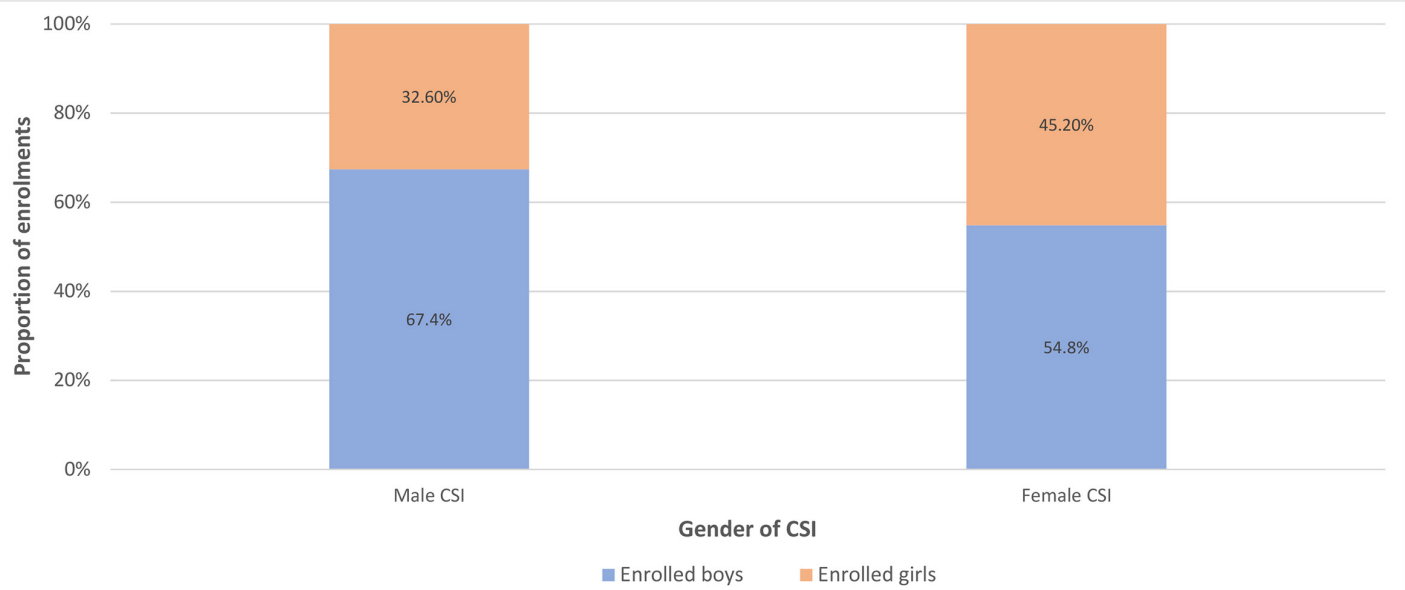

Figure 1 Enrolments of children by community swimming instructor (CSI) gender ( $N=11564)$.

Socialisation theory forms the underlying idea for gender analyses of public health programmes. This theory maintains that differences in behaviour between genders are not based on biology, but rather socially learnt behaviours applied and enforced on each gender within a culture. ${ }^{26}$ Hence, community programmes/interventions can change these perceptions and attitudes in communities to alter expectations on roles and behaviour by gender. Gender analyses seek to identify opportunities where cultural attitudes can be changed to allow people to behave based on their individual needs, rather than their gender.

A framework analysis methodology was applied for this gender analysis through a deductive approach, where impacts of the programme on gender norms and behaviours were coded against the Gender Integration Framework by Family Health International 360, Table $1 .{ }^{1}$ This framework assumes that gendered norms, behaviours and outcomes are reflective of culture, and are malleable. Specific subthemes under each domain were inductively developed based on content analysis of the interviews and observations, identifying common and divergent genderbased effects and the causes behind these as stated by participants. This framework organises the range of gender-based effects found in the literature to allow for analysis as depicted in figure 1 . The framework captures both a range of possible external (on outward behaviours and roles) and internal (on norms and attitudes) effects of the programme, and is designed to be used in community-based settings. It also identifies the effects of each of these domains on programme delivery. The framework has also been used to conduct gender analyses in community-based programmes addressing HIV, gender-based violence and food insecurity in LMICs. ${ }^{27} 28$

\section{Quantitative and qualitative data sources}

The framework was applied on data from primary quantitative and qualitative data sources. Quantitative data consisted of routine programme information collected by programme delivery staff via standardised instruments. Qualitative data were collected by data collectors in Bengali across all three upazilas through observations, in-depth interviews (IDIs) and focus group discussions (FGDs). Data collectors were extensively trained on the use of the tools, consent procedures, qualitative interview and field note methods and study aims and objectives.

Programme data were analysed to calculate gender differences in participant attendance, drop out,

\begin{tabular}{|c|c|c|}
\hline Domain & Sources of information & Examples of key gender relations, barriers and opportunities \\
\hline 1. Access to resources & $\begin{array}{l}\text { Programme data } \\
\text { IDIs and FGDs } \\
\text { shadowing }\end{array}$ & $\begin{array}{l}\text { Education, information, services, employment, benefits, freedom of } \\
\text { movement, transport }\end{array}$ \\
\hline 2. Knowledge, beliefs, perceptions & $\begin{array}{l}\text { IDls and FGDs } \\
\text { shadowing }\end{array}$ & $\begin{array}{l}\text { Beliefs about capabilities, self-efficacy and confidence, acceptable } \\
\text { behaviour and value in society, child safety and protection }\end{array}$ \\
\hline 4. Legal rights and status & $\begin{array}{l}\text { Programme data } \\
\text { IDIs and FGDs }\end{array}$ & $\begin{array}{l}\text { Employment contracts and rights, biases in governance and policy at } \\
\text { programme and institutional level }\end{array}$ \\
\hline 5. Power & $\begin{array}{l}\text { IDIs and FGDs } \\
\text { shadowing }\end{array}$ & $\begin{array}{l}\text { Autonomy, household financial control, control over resources, decision } \\
\text { making within the household and in the community }\end{array}$ \\
\hline
\end{tabular}

FGD, focus group discussion; IDI, in-depth interview. 
Table 2 Programme/secondary data sources

\begin{tabular}{ll}
\hline Instrument & Data available \\
\hline Enrolment form & Gender differences in children enrolled \\
Attendance book/ register & $\begin{array}{l}\text { Gender differences in children enrolled for men and women CSIs } \\
\text { Gender differences in child drop out }\end{array}$ \\
HR data & Differences in course completions between men and women CSIs \\
& Gender trends in recruitment and resignation of programme staff \\
\hline
\end{tabular}

CSI, community swimming instructor; HR, human resource.

graduation rates and other metrics. Human resources data were also analysed to understand gender differences in community staff recruitment and attrition. Table 2 outlines these instruments and the quantitative information available from each.

Qualitative data collection was guided by the consolidated criteria for reporting qualitative research guidelines for qualitative research (see online supplemental file 3 for checklist). ${ }^{29}$ Data were collected from a range of stakeholders in contact with the programme of both genders. A distinction between sex and gender was not made due to cultural constraints, but participants were recruited based on the gender they identified with. The IDIs, FGDs and observations took a semistructured format using interview and observation tools developed in accordance with the Gender Integration Framework.

Three female and two male data collectors (led by NCD) with backgrounds in anthropology were engaged. Data collectors were recruited by the implementing agency to conduct the data collection and were fluent in both English and Bengali, with previous experience in qualitative data collection. They were provided training from the researchers on the use of the tools and data collection methodologies.

Qualitative data were collected in two phases from September to October 2018 and February to March 2019. Phase 1 data were analysed and informed key themes for exploration in phase 2. Each phase involved approximately the same number of IDIs and FGDs. In both phases, programme staff were recruited purposively to provide insights on gender-related programme delivery challenges and community responses. Programme staff were introduced to data collectors through headquarter staff and supervisors. Programme staff included: CSIs, CSI trainers, VIPC and UIPC members, and staff employed to monitor and manage the programme including supervisors and programme headquarter staff. Programme staff were included if they were involved in programme implementation and oversight for at least the past 12 months. Teachers who were sometimes involved in facilitating participation of school children were also interviewed. CSIs, VIPC and UIPC members detailed community responses to gender-based roles and norms challenged or adhered to by the programme. Both men and women were interviewed. Supervisory staff provided insights into how gender roles and norms shaped attitudes and uptake of the programme. All supervisory staff were men, except two female CSI trainers. Key staff from the implementing organisation were interviewed for a second time in phase 2 to follow-up specific findings from phase 1 that required further explanation.

To understand programme beneficiary experiences, parents and children in communities who had contact with the programme were recruited. Participants were chosen from programme lists to ensure a range of ages, genders and locations were covered. Beneficiary participants included children who were enrolled in or had completed the programme, parents of children enrolled in the programme, parents of children who had enrolled but then dropped out and parents who had been approached by SwimSafe staff but refused to enrol. Both mothers and fathers were engaged to identify differences in perspectives by gender.

All tools were field tested before finalisation. Tools were updated in phase 2 to reflect themes that required further exploration after phase 1 . Snowball sampling was used to reach community-level participants to form focus groups. See online supplemental files 4 and 5 for phases 1 and 2 tools used to explore gender-related issues for this study.

All participants were recruited and interviewed face to face for the study, except two programme headquarters staff who were recruited and interviewed over the phone. All IDIs and FGDs were audio recorded and held in private locations appropriate for participants, such as their home, the local school or a cyclone shelter. Field notes of main findings were taken. Only the interviewer and a note taker were present at IDIs and FGDs. IDIs and FGDs took between 30 and $90 \mathrm{~min}$. Data collection ceased once main findings became saturated, as assessed with the field notes.

Two SwimSafe classes in session were observed.

\section{Patient and public involvement}

Tools were field tested with community members and implementing staff and updated on their response and feedback. Phase 1 findings were presented to field implementing staff who guided the questions and themes for follow up in phase 2, ensuring the findings were relevant for implementation improvement. Implementing staff shared findings with communities through VIPC and UIPC meetings. 


\section{Consent}

Informed written consent was sought from all participants. Where literacy was a barrier, consent was taken verbally and participants provided fingerprints. All participants were informed that the data would be used to improve the delivery of the SwimSafe programme, and that data collectors were acting independently from the programme implementers. Written consent for child participants was obtained from their parents or guardian.

\section{Analysis}

Quantitative data were analysed using SPSS V 21 to identify differences between genders in recruitment, class enrolment, drop out and graduation rates. ${ }^{30}$ Differences in rates and proportions between groups in programme data were analysed using bivariate Pearson $\chi^{2}$ tests and trends analysed using $\chi^{2}$ linear-by-linear associations.

All qualitative data were transcribed in Bengali and translated into English for analysis by professional services. A fluent Bengali and English speaker completed a quality check on all documents to ensure accuracy. Transcripts were not returned to participants due to logistical difficulties in finding rural participants and low literacy.

Analysis of the transcribed qualitative data was assisted by NVivo V.12 software. ${ }^{31}$ Thematic analysis was guided by the Gender Integration Framework. ${ }^{1}$ The framework was used to generate codes and incorporate both deductive (predetermined) and inductive (emergent) thematic analysis. This approach allowed for the exploration of specific themes (eg, gender-based barriers and facilitators of implementation) while not restricting the identification of unanticipated themes. Two independent teams of researchers, each with three coders (lead by MG, SP and NCD), initially coded the data before discussing discrepancies and identifying final themes.

Our analysis identified where the SwimSafe programme may be categorised along the Gender Integration Continuum, ${ }^{1}$ which describes whether the programme is gender exploitative, accommodative or transformative. Exploitative programmes take advantage of and perpetuate harmful gender norms to meet outcomes, while accommodative programmes may acknowledge or cater to gender norms. Transformative programmes actively seek to change gender norms to improve health and other outcomes for men and women where they are disadvantaged.

\section{RESULTS}

We found insights into how involvement in the SwimSafe programme as a CSI, parent, child or wider community member affected gender roles, norms and attitudes and opened new opportunities for women. The quantitative and qualitative results are presented using the Gender Integration Framework domains. No data were reported against the framework domain of Legal rights and status as this referred to the impacts of men and women's legal status in the wider context of Bangladesh.
Quantitative data from enrolment forms were available for 11564 children, and data from graduation forms were available for 11577 children from February to December 2018. Data from the recruitment of 229 CSIs were also included from January 2017 to December 2018. Missing data from all sources were less than $3 \%$.

Twenty IDIs and three FGDs were conducted with programme beneficiaries covering mothers, fathers and enrolled children. Thirty-seven IDIs were held with programme providers including CSIs, supervisors and programme headquarter staff. Four of these were repeat interviews of area and project coordinators. One FGD was held with women CSIs to understand organisational and community-level perspectives. Two SwimSafe classes were observed to understand programme engagement and participation. Less than $10 \%$ of potential participants approached refused to participate. The participants are listed in table 3.

In addition, two observations of SwimSafe classes were conducted. Additional observations were not possible due as data collection coincided with the end of the SwimSafe season.

\section{Access to resources}

We found that employment in SwimSafe granted women CSIs with greater access to resources such as education and material goods including mobile phones and clothing. In addition, the CSI role gave women the opportunity for legitimate mobility even in the face of restrictive social norms. Many women CSIs and CSI trainers were previously unable to move beyond their community and were now travelling within their upazila for training and child enrolment. This in turn increased community acceptance of women CSI movement for non-SwimSafe-related activities, such as visiting markets in farther areas. This increase in mobility was limited for those in more conservative communities, however, such as where the parda (veil) system was common and women were not allowed to engage directly with men.

Earlier her movement was confined within a few houses. How she has travelled to faraway places to teach swimming. Now people respect her. [Supervisory staff, Male]

However, a divergent theme identified was that although women CSIs were becoming more mobile, the larger ecosystem to support women's movement was unchanging which prevented the hiring of female supervisors. Field supervision staff believed that women supervisors would have difficulty with mobility. Male supervisors rode their own motorbikes and it was perceived as inappropriate for women to do the same. The implementing organisation was also concerned for women's safety at night due to the lack of secure public transportation options.

She will not get any transportation in the evening to get back to your place. It becomes risky for a lady to travel alone at night. [Supervisory staff, Male] 
Table 3 Participants and qualitative sample sizes for IDIs and FDGs

\begin{tabular}{|c|c|c|c|c|c|}
\hline \multirow[b]{2}{*}{ Participant role } & \multicolumn{2}{|c|}{ IDIs } & \multicolumn{3}{|c|}{ FGDs } \\
\hline & Male & Female & Male & Female & Both \\
\hline Children enrolled or graduated from program & 3 & 4 & 0 & 0 & 1 \\
\hline Parents of children who dropped out of the programme & 2 & 3 & 0 & 0 & 0 \\
\hline Parents who refused to enrol their children in the programme & 2 & 2 & 0 & 0 & 0 \\
\hline Area coordinator & 3 & 0 & 0 & 0 & 0 \\
\hline SwimSafe field manager & 1 & 0 & 0 & 0 & 0 \\
\hline Programme coordinator & 1 & 0 & 0 & 0 & 0 \\
\hline $\begin{array}{l}\text { Village Injury Prevention Committee and Union Injury Prevention Committee } \\
\text { members }\end{array}$ & 8 & 1 & 0 & 0 & 0 \\
\hline Trainers of community swim instructors & 0 & 2 & 0 & 0 & 0 \\
\hline Total & 37 & 20 & 1 & 2 & 1 \\
\hline
\end{tabular}

FGD, focus group discussion; IDI, in-depth interview.

CSIs of both genders gained financial independence from their salary. The impact of this was higher for women as they had few other employment opportunities in rural communities, while men often worked other jobs. Male CSIs often spent money on their personal entertainment such as eating in local markets with friends, while women often spent their income on their families or own education.

It feels good that I can spend the money as I want. I can give something to my parents when I get money... and spend on my studies. [CSI, Female]

Both men and women CSIs were able to develop new communication skills that made them more employable. However, this was valued by women CSIs due to lack of other capacity-building opportunities. Their involvement also broke down family perceptions around women's working ability, making employment more acceptable.

If I speak truly, earlier I was not even be able to talk with people properly. I could not communicate properly even with my family members, I felt very uneasy. And I was very introverted. [CSI Trainer, Female]

\section{Knowledge, beliefs and perceptions}

We found that gendered perceptions around culturally appropriate gender roles and capabilities impacted the hiring of staff within the implementing organisation because of which no women supervisors were hired. In addition, the pond structures required regular maintenance by supervisors. It was believed that women supervisors could not manage the transportation of building materials, lifting and helping with material movement both due to their physical attributes, and due to the community perception that managing labour was a 'man's job'.

Supervisors need to help the labourers when transporting bamboo-we also lift the bamboo and push the van. The work we are doing is not possible for women. [Supervisory staff, Male]

The perceived inability of women to manage the bamboo structure was shared with women CSIs and supervisors. There were varying levels of confidence among women CSIs on platform repair-some women CSIs conducted minor repairs, but others were not working with the structure at all. Many women CSIs used their male family members for maintenance work, while for others the implementing organisation was required to hire more labour to repair platforms of women CSIs. This had implications for cost and time for some ponds.

I told a woman CSI to tie a bamboo but she didn't do it. In that case, the work must be done by hiring people. As she is a woman she can't do this work. We [Supervisors] have to wait there while the repair work is done. [Supervisory staff, Male]

Gendered interactions and increased visibility of the CSIs and CSI trainers were often stigmatised by members of the community. Some women CSIs and CSI trainers reported facing negativity from community members for interacting with male supervisory staff and VIPC members. However, negative community behaviour towards CSIs was reduced when they received support from their families to engage in the work.

At first I had faced some problems...with comments from the community. My mother supports me a lot. I 
have a sister; she also supports me a lot. So, I have no problem in doing this work. [CSI, Female]

Women CSIs used the programme's social purpose to respond to community negativity. Work involving children and community betterment was considered appropriate for women, given their inherent gender-based role as child carers. Participants reported that over time, negative attitudes towards women's work and mobility were changing as the community was exposed to the programme.

They [the community] say the girl has reached the age of marriage, so why don't you marry her off rather than let her travel to cities [with the program]. So, to manage them I say that this is social work. Then they understand that their children are saved from drowning because of us, and they support us wholeheartedly. [CSI Trainer, Female]

Perhaps due to the small sample size of men CSIs, there were no statistical differences found between the rate of drop out for men and women CSIs. However, all supervisors reported that men CSIs were more difficult to recruit and retain than women CSIs. Many men CSIs found the part time, lower pay nature of work to be less prestigious, especially for the educational qualifications required. They were also more likely to seek full-time work, given their roles as primary bread-winners of the family. On the other hand, men who were currently studying did not express this issue, as part-time work suited them. Entering the water was also seen by some as more appropriate to lower socio-economic groups, and hence offensive.

They [male CSIs] don't take it positively to teach children swimming by getting down into the water. They think that it is lower class work. [Supervisory staff, Male]

The programme contributed to changing the social attitudes and perceptions regarding women's work outside the home. CSI supervisors noted that because of the visibility of many female CSIs in their roles, community members have become more receptive of the work of women outside the home in the field of health and education. However, despite greater acceptability of women's employment, women remained largely responsible for household work and were expected to be at home more frequently than men. Hence, women had lower expectations from both themselves and the wider community to work in lucrative and respected occupations, so were more accepting of the part-time nature of the work. Women CSIs therefore reported dissatisfaction with the pay less often, even if they had the same educational qualifications as male CSIs.

Because if males work part time anywhere they expect more than the girls, even if his skill and educational qualification are not high. In some cases, women are more qualified than the men candidates. Male candidates are less interested in this job because of the mismatch between the payment and their expectations. [Supervisory staff, Male]

Supervisory staff also reported that women CSIs were better able to engage with mothers to send their children to SwimSafe classes as it was more appropriate for women to speak with them. Women CSIs were also considered more sincere and hardworking.

The benefit is that women CSIs can move from house to house and talk with children's mothers. [Supervisory staff, Male]

\section{Practices and participation}

Enrolment data showed that fewer girls $(43.5 \%$; $\mathrm{n}=5030$ from 11564 enrolled children; $95 \%$ CI $42.6 \%$ to $44.4 \%$ ) enrolled in the SwimSafe programme compared with boys. Analysis of men and women's practices and participation found that this was due to cultural barriers where it was considered less appropriate for girls to enter water in public spaces. Parents were concerned for their girls' reputation and safety, and were even less likely to enrol older girls when the CSI was men. While $45.2 \%$ ( $\mathrm{n}=4503$ from 9960 children; $95 \%$ CI $44.2 \%$ to $46.2 \%$ ) of enrolments were girls for women CSIs, this proportion dropped down 32.6\% ( $\mathrm{n}=523$ from 1604 children; 95\% CI $30.3 \%$ to $34.9 \%$ ) for men CSIs (figure 1 ). To cater for this issue of girls' participation, the implementing organisation hired a larger number of women CSIs in its second year of operation.

Parents feel comfortable when their girls learn swimming from a women trainer, because they do not want to hand over a growing girl to a male trainer. There are some social barriers, some familial barriers... [Supervisory staff, Male]

The results showed that the proportion of girls enrolled in SwimSafe classes significantly decreased as age increased $(\mathrm{p}=0.021)$, again due to perceptions around inappropriate exposure of older girls in front of men (figure 2). Older girls also reported feeling shy to attend classes, especially in front of male CSIs or if the pond was near a road or other public area such as community courtyards or health centres that exposed them to other community members.

Now I think they [girls] don't attend because of the presence of males or because everyone comes [to the pond] to see them. Maybe they would've gone down to learn if everybody there was a woman. [CSI, Male]

Gender-based roles and responsibilities also reduced the likelihood of girls finishing the programme. Girls were $55.5 \%$ ( $\mathrm{n}=611$ of 1099 children; $95 \%$ CI $52.6 \%$ to $58.5 \%$ ) of children who dropped out of the programme part way. Analysis of gender-based practices revealed that girls often assisted with care of younger siblings or household work. The same roles were not prescribed to boys. 


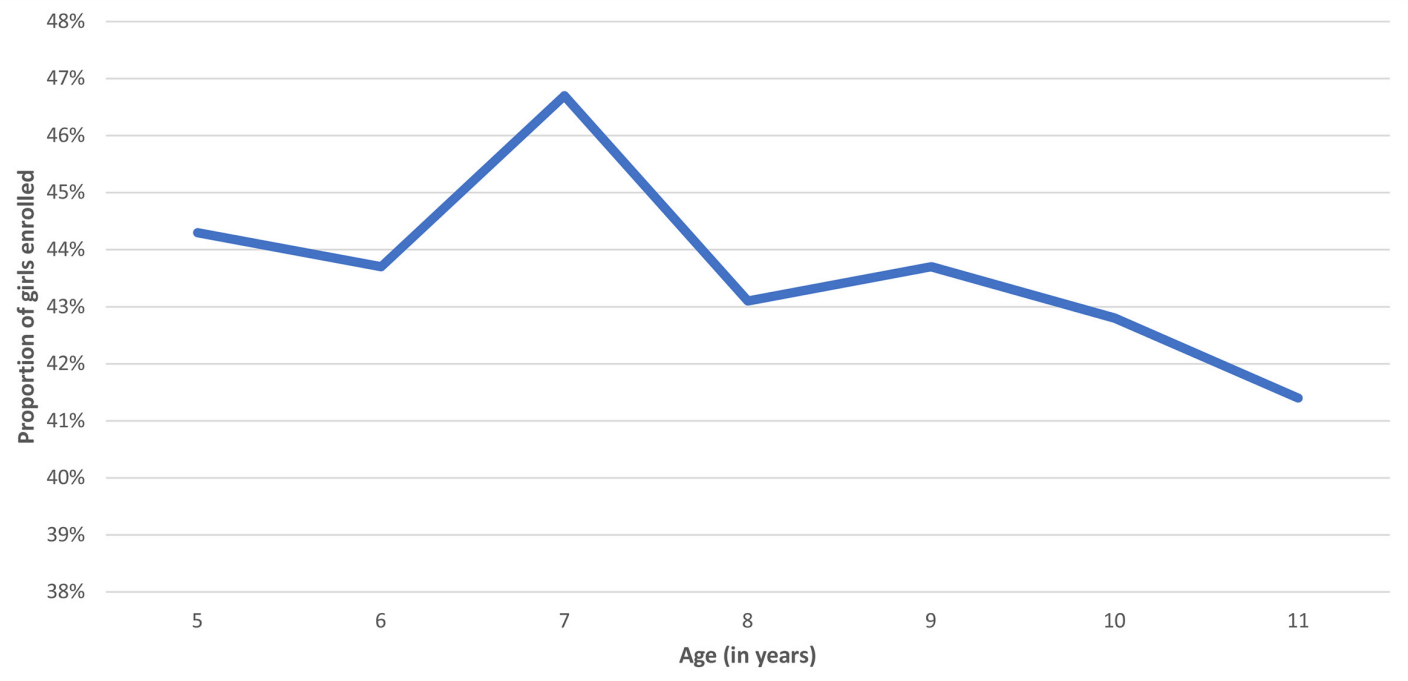

Figure 2 Proportion of girl enrolment by age.

It was also less acceptable for girls to move around the community alone and regularly access the pond.

She has a little sibling. She has to keep her sibling with her. Besides this, she has to do the household work. [Dropout child's parent, Female]

In villages they do not care much about boys and about where they are going. But for girls the rules are strict. [CSI, Female]

Norms around appropriate practices for girls also affected the approach to clothing. Older girls took into consideration cultural concerns around modesty by wearing long tunics, although this extra material was cumbersome while learning. Older girls adapted by tying a cloth around their waist to better hold down their tunics. Some women CSIs provided private areas where girls could change from their wet clothes before travelling home to ensure comfort.

It is not possible [to wear leggings] for older girls. They have to wear extra clothes. They tie the extra loose cloth to their waist with a belt. [Graduated child's parent, Female]

At the village level, VIPCs had more men than women members. Women often faced barriers to attend VIPC meetings due to the parda (veil) system in some communities where women were not allowed to communicate directly with men. Some men from VIPCs reported that women were less preferred since they were not able to travel around communities to manage implementation.

No, I think It's better to engage two men in those empty positions [of the VIPC committee]. Two women are enough for us... Men can go everywhere. [VIPC Member, Male]

Although many participants perceived women as less capable VIPC members, a divergent finding was that women VIPC members expressed having more time and motivation to engage the community and make monitoring visits to ponds compared with men, who were often busy with work. Many VIPC participants agreed that an equal number of men and women were required in the VIPC, but this was not actively implemented during VIPC formation.

The VIPC members are mostly men, but they have a lot of work and they are busy...But when we want help, the women members always try. [Supervisory staff, Male]

\section{Power}

Women CSIs appeared to have less power than male CSIs to make decisions on their career, such as participating in the programme as CSIs. In particular, married CSIs were often at the bottom of the hierarchy in their homes and were more difficult to recruit, as they needed permission from both in-laws and husbands. Women CSIs gathered support from their families by bringing them to the field offices at the time of recruitment to meet the implementing team and assuage their concerns.

I took them [my family] to show my new office. I introduced them to my Supervisor ... So, I convinced my family members through him. [CSI, Female]

We found no evidence that employed women experienced greater harassment at home due to their increase in earnings. In fact, some CSIs reported their families were more cognisant of their opinions as they contributed to household income.

\section{Other findings}

While women CSIs gained in mobility and financial independence, their access to gender-specific information that affected job performance was limited, including menstruation management. Training did not provide guidance on how women CSIs should manage classes 
during this time. Some CSIs were teaching children from the shore when they were menstruating, which may have presented a safety hazard. Some CSIs were also confused about possible health impacts of running classes in water while menstruating. As all supervisors are men, women CSIs are unable to be transparent about menstruation and would feign illness.

I tell him [Supervisor] "I am feeling cold, I won't get down in water today. I will stay above the structure..." We do not explain exactly what is wrong, we manage it by ourselves. [CSI, Female]

\section{Categorisation of SwimSafe on the gender integration continuum}

The SwimSafe programme is a gender accommodating programme. The programme identified gender-based constraints and catered to them so that the programme was implementable in communities. For example, SwimSafe preferentially hired more women CSIs in 2018 after identifying they were easier to retain and that girl children were more comfortable.

However, opportunities to systematically address gender-based constraints were missed. Some CSIs identified lower participation of girls in classes and introduced adaptations to increase girl attendance. They taught children in gender-segregated groups both to appease parents and due to the belief that girls required more attention to teach swimming than boys. However, these strategies were not systemised across all classes.

It's good to teach them separately. Girls need time and boys learn faster. Boys can learn faster what I teach them. But girls need extra care. [CSI, Male]

\section{DISCUSSION}

The SwimSafe programme was found to have a range of impacts on gender norms, roles and relationships. The programme was a gender accommodating programme as it adapted implementation to gender perceptions and expectations. ${ }^{1}$ However, the analysis revealed opportunities for SwimSafe to become more gender transformative in order to address negative gender-related impacts to health.

First, gender-transformative activities are required to ensure girls and boys are equally represented in swimming classes. Lower attendance of girls not only increases in their risk of drowning, but may be reflective of the global trend of keeping girls at home to complete domestic work, reducing their ability to play and engage in physical exercise. This has negative implications for girls' development. ${ }^{32}$ Our results also paralleled findings that show families become more restrictive of girls as they grow to protect their honour. ${ }^{33}$ Activities that encourage families to change their perceptions around girls' and boys' roles on housework and mobility may be considered by SwimSafe. For example, women CSIs have benefited from increased mobility and financial independence. Showcasing these benefits to families may change attitudes around girls' movement and employment. The programme can also identify adaptations of some CSIs that improve girls' participation and implement these systematically across the programme, such as providing private changing spaces. Communication of the differences in participation to communities may also enable a more supportive environment for girls. Programmes in Bangladesh that engage girls' wider ecosystem for support to make changes have had greater success in changing norms. ${ }^{34}$

Equal access to employment for women has health benefits for all genders. Earning women are able to efficiently access resources such as medicines without depending on others, and men may experience a reduction in stress and take on less risky work if they are not the sole breadwinner. ${ }^{13} 203536$ The SwimSafe programme is already moving towards improving the health of families by providing employment to local women.

The SwimSafe programme could go further in changing norms around women's employment by hiring women supervisors. Women in supervision roles could contribute to changing organisational and community perceptions around women's leadership capabilities. The lack of women supervisors deprives communities of women leader role models and reinforces beliefs about appropriate work for women. Additionally, excluding women because of less access to transport devalues women, as men are then able to access a wider range of resources and opportunities. ${ }^{37}$ The SwimSafe programme should consider employing strategies to support women where they face barriers at work, such as in transport and bamboo management. To cater for cultural concerns, specific transport providers may be engaged for women supervisors, or they may be allocated communities closer to home, although this has implications for overall programme cost and cost effectiveness. ${ }^{38}$ Increased participation of women in leadership roles has been associated with greater focus on public health initiatives, and taking steps towards normalising women in these positions may have positive health outcomes for communities in the long run. ${ }^{39-41}$ For example, women local government leaders in India are more likely to promote immunisation programmes, girls' education and women's employment. ${ }^{42}$

Women CSIs low involvement in bamboo management reinforces women's lack of confidence and perceptions of incapability in performing labour-related work. Specifically, upskilling women CSIs in bamboo management may change limiting internalised and externalised beliefs. This will not only reduce programme costs but may also contribute to widening of opportunities for women by encouraging them to engage in other physically demanding employment. ${ }^{18} 43$ Gendered constraints around physical activity more generally prevent women from engaging in healthy behaviours, and should be challenged to reduce the burden of noncommunicable diseases. ${ }^{44}$ However, incorporating high levels of physical labour may limit the number of women willing to take on the work due to internalised restrictive beliefs in this context.

The acceptability of part-time work for women CSIs reflects wider standards in LMICs of treating community health 
workers as volunteers. Because community health workers are primarily women, institutions are more likely to manage these workers less formally because gender roles allow them to. Women are also more likely to accept this situation given that formal work is not considered a woman's primary role. ${ }^{1013}$ In many contexts globally, men working the same roles have not accepted the pay and type of roles that women have accepted. ${ }^{13}$ Similarly, in SwimSafe, men CSIs were less satisfied with the hours and pay as it was below what they may earn elsewhere. The programme should consider strategies to reduce rather than reinforce these beliefs around the standards to which men and women are remunerated and treated in the workplace, such as ensuring market-rate pay that men would also be satisfied with and findings avenues for career growth. ${ }^{13}$

The importance of women's involvement in program-level decision-making was made clear by the lack of consideration given to menstrual hygiene, which was not addressed in training by the men supervisory staff. Menstruation may also be a reason why older girls were not enrolling in the SwimSafe programme. In South-Asian countries, social taboos and lack of representation of women in decision-making lead to menstruation being ignored in health and sanitation programmes, ${ }^{46}$ and specific strategies such as training women CSIs to have these conversations when engaging with girls and their mothers may be required. CSIs should also re-engage drop out girls to ascertain whether they are leaving the programme for this reason and encourage them to join the next batch. Women supervisors should be recruited to support men CSIs in these talks. To ensure equitable reach of the programme to girls and tailored support to women workers, women's leadership and involvement in programme design and implementation are essential. ${ }^{44} 47$ However, it's essential that male community leaders and implementing staff demonstrate respect to female leaders if they are to be taken seriously, and so men need to be simultaneously sensitised to the value of women voices and participation. ${ }^{48}$

\section{Methodological challenges}

No findings were reported for the Legal rights and status framework domain. To identify impacts of the policy and law environment on gender, a longer study period with participation of local government-level key informants may be required. In addition, findings on the impact of gender norms on menstruation management did not fit in any of the Gender Integration Framework domains. The framework may benefit from another domain assessing the effect of gender on interpersonal interactions.

Another limitation of this study was that phase 2 data collection occurred after the end of the SwimSafe season, and some respondents may have forgotten their initial experiences of the programme. We were also only able to conduct two observations before the close of the season, limiting value of findings from the observation data. In addition, an FGD with male CSIs was not possible due to the small numbers, which reduced our understanding of group-based perceptions of male workers in this context. Lastly, there were no women supervisors who could provide a women's perspective on the possible gender-based constraints of the role.

\section{CONCLUSIONS}

While the SwimSafe programme is changing some community-wide perceptions around women's mobility and work, further opportunities exist to challenge gender-based norms and relationships to improve health outcomes for both genders. The programme may consider how activities are re-enforcing certain norms, such as expectations around women's formal work, and find strategies to challenge these norms instead. Systemised strategies are also required to ensure equal participation of girls and boys in classes to ensure equitable protection from drowning.

The methods and findings may be useful for other community-based programmes to assess the wider impacts of their programmes on gender and address health outcomes beyond targeted ones. In particular, the Gender Integration Framework provides a comprehensive list of domains of impact that can be analysed for those implementing programmes.

\section{Twitter Medhavi Gupta @MedGupta}

Acknowledgements SwimSafe is implemented by Centre for Injury Prevention and Research, Bangladesh. The program is funded by Royal National Lifeboat Institution, UK (RNLI). The data collection and analysis of this report was supported by a dedicated team of researchers. Thank you to the research team for your hard work: Shamima Easmin, Rabeya Akter Konika, Pranoy Saha, Md. Reazul Islam and Rumana Afroz Srabony.

Contributors AR, JJ, RI, DN and MG conceptualised research questions and methods. MG and NCD developed tools with support from SP, AR, DN and JJ. MG, SP and NCD led analysis of results. MG drafted and edited publication with inputs from AR, JJ, RI, DN, SP, MSH and NCD.

Funding This project is funded by the Royal National Lifeboat Institution (RNLI) UK (Award/Grant number is not applicable). RNLI provided guidance on key research questions and data collection methods at the inception of the project.

Competing interests None declared.

Patient consent for publication Not required.

Ethics approval Local ethical approval from the Centre for Injury Prevention and Research, Bangladesh was granted (Memo no: CIPRB/ERC/2017/24). Ethical approval was also obtained from the University of New South Wales Human Research Ethics Committee (HC: 180608).

Provenance and peer review Not commissioned; externally peer reviewed.

Data availability statement Data are available upon reasonable request. The datasets used and/or analysed during the current study are available from the corresponding author on reasonable request. Please email Jagnoor Jagnoor ( jjagnoor1@georgeinstitute.org.in).

Supplemental material This content has been supplied by the author(s). It has not been vetted by BMJ Publishing Group Limited (BMJ) and may not have been peer-reviewed. Any opinions or recommendations discussed are solely those of the author(s) and are not endorsed by BMJ. BMJ disclaims all liability and responsibility arising from any reliance placed on the content. Where the content includes any translated material, BMJ does not warrant the accuracy and reliability of the translations (including but not limited to local regulations, clinical guidelines, terminology, drug names and drug dosages), and is not responsible for any error and/or omissions arising from translation and adaptation or otherwise.

Open access This is an open access article distributed in accordance with the Creative Commons Attribution Non Commercial (CC BY-NC 4.0) license, which permits others to distribute, remix, adapt, build upon this work non-commercially, and license their derivative works on different terms, provided the original work is 
properly cited, appropriate credit is given, any changes made indicated, and the use is non-commercial. See: http://creativecommons.org/licenses/by-nc/4.0/.

\section{ORCID iD}

Medhavi Gupta http://orcid.org/0000-0002-6558-8373

\section{REFERENCES}

1 FHI 360. Gender Intergration framework: how to integrate gender in every aspect of our work, 2013.

2 Moser C. Gender planning and development: theory, practice and training. London: Routledge, 1993.

3 Wilkinson RG, Marmot M. Social determinants of health: the solid facts. World Health organization, 2003.

4 Amin S. The poverty-Purdah trap in rural Bangladesh: implications for women's roles in the family. Dev Change 1997;28:213-33.

5 Coker AL, Smith PH, Thompson MP, et al. Social support protects against the negative effects of partner violence on mental health. $J$ Womens Health Gend Based Med 2002;11:465-76.

6 Schuler SR, Bates LM, Islam F, et al. The timing of marriage and childbearing among rural families in Bangladesh: choosing between competing risks. Soc Sci Med 2006;62:2826-37.

7 Vlassoff C. Gender differences in determinants and consequences of health and illness. J Health Popul Nutr 2007;25:47-61.

8 Strauss J, Gertler PJ, Rahman O, et al. Gender and life-cycle differentials in the patterns and determinants of adult health. J Hum Resour 1993;28:791-837.

9 Bates LM, Hankivsky O, Springer KW. Gender and health inequities: a comment on the final report of the WHO Commission on the social determinants of health. Soc Sci Med 2009;69:1002-4.

10 Maes K, Closser S, Vorel E, et al. A women's development army: narratives of community health worker investment and empowerment in rural Ethiopia. Stud Comp Int Dev 2015;50:455-78.

11 Steege R, Taegtmeyer M, McCollum R, et al. How do gender relations affect the working lives of close to community health service providers? Empirical research, a review and conceptual framework. Soc Sci Med 2018;209:1-13.

12 Najafizada SAM, Bourgeault IL, Labonté R. A gender analysis of a national community health workers program: a case study of Afghanistan. Glob Public Health 2019;14:23-36.

13 Closser S, Napier H, Maes K, et al. Does volunteer community health work empower women? Evidence from Ethiopia's women's development army. Health Policy Plan 2019;34:298-306.

14 Correa-De-Araujo R. Serious gaps: how the lack of sex/genderbased research impairs health. J Womens Health 2006;15:1116-22.

15 Madell DE, Hayward BP. Gender inequities and global health outcomes. J Glob Health Rep 2019;3:e2019017.

16 Vyas S, Watts C. How does economic empowerment affect women's risk of intimate partner violence in low and middle income countries? A systematic review of published evidence. J Int Dev 2009;21:577-602.

17 Laverack G. Improving health outcomes through community empowerment: a review of the literature. $J$ Health Popul Nutr 2006;24:113-20.

18 Keleher $\mathrm{H}$, Franklin L. Changing gendered norms about women and girls at the level of household and community: a review of the evidence. Glob Public Health 2008;3 Suppl 1:42-57.

19 Dworkin SL, Colvin C, Hatcher A, et al. Men's perceptions of women's rights and changing gender relations in South Africa: lessons for working with men and boys in HIV and antiviolence programs. Gend Soc 2012;26:97-120.

20 Hashemi SM, Schuler SR, Riley AP. Rural credit programs and women's empowerment in Bangladesh. World Dev 1996;24:635-53.

21 World Bank Group. Gender data portal: Bangladesh [Internet], 2017. Available: http://datatopics.worldbank.org/gender/country/ bangladesh [Accessed 04 Jul 2020].

22 Georgetown Institute for Women Peace and Security and Peace Research Institute Oslo. Women peace and security index 2019/20: tracking sustainable peace through inclusion, justice, and security for women. Washington, DC: GIWPS and PRIO, 2019.

23 Gupta M, Rahman A, UI Baset K, et al. Complexity in implementing community drowning reduction programs in southern Bangladesh: a process evaluation protocol. Int J Environ Res Public Health 2019;16. doi:10.3390/ijerph16060968. [Epub ahead of print: 18 Mar 2019]

24 Rahman A, Alonge O, Bhuiyan A-A, et al. Epidemiology of drowning in Bangladesh: an update. Int J Environ Res Public Health 2017;14. doi:10.3390/ijerph14050488. [Epub ahead of print: 05 May 2017].

25 Meddings D, Hyder AA, Ozanne-Smith J, et al. Global report on drowning: preventing a leading killer. Geneva, Switzerland: World Health Organization, 2014.

26 Carter M. Gender socialization and identity theory. Soc Sci 2014;3:242-63.

27 Geleta EB, Elabor-Idemudia P, Henry C. Scaling-up: Gender integration and women's empowerment in Southern Ethiopia. Cogent Food Agric 2017;3:1415100.

28 USAID, Advancing Partners \& Communities (APC). The added value of gender integration: promising practices from the advancing partners \& communities project Washington, DC: APC, 2019. Available: https://www.advancingpartners.org/resources/technicalbriefs/added-value-gender-integration

29 Tong A, Sainsbury P, Craig J. Consolidated criteria for reporting qualitative research (COREQ): a 32-item checklist for interviews and focus groups. Int J Qual Health Care 2007;19:349-57.

30 IBM Corp. Ibm SPSS statistics for windows. Armonk, New York, 2017.

31 QSR International Pty Ltd. NVivo qualitative data analysis software, 2018.

32 United Nations Children's Fund. Harnessing the power of data for girls: taking stock and looking ahead to 2030. New York, NY: United Nations Children's Fund (UNICEF) Division of Data, Research and Policy, 2016.

33 Presler-Marshall E, Stavropoulou M. Adolescent girls' capabilities in Bangladesh: A synopsis of the evidence London. United Kingdom: Gender and Adolescence: Gobal Evidence, 2017.

34 Katz E. Programs promoting young women's employment: What works? Washington, D.C.: The World Bank, 2008.

35 Karim R, Lindberg L, Wamala S, et al. Men's perceptions of women's participation in development initiatives in rural Bangladesh. Am J Mens Health 2018;12:398-410.

36 Graham H. Hardship and health womens lives. New York, NY: Routledge, 1993.

37 Cook N, Butz D. Gendered mobilities in the making: moving from a pedestrian to vehicular mobility landscape in Shimshal, Pakistan. Soc Cult Geogr 2018;19:606-25.

38 Vong S, Ros B, Morgan R, et al. Why are fewer women rising to the top? A life history gender analysis of Cambodia's health workforce. BMC Health Serv Res 2019;19:595.

39 Bhalotra S, Clots-Figueras I. Health and the Political Agency of Women. In: Discussion paper series. Germany, 2011: e8.

40 Dhatt R, Theobald S, Buzuzi S, et al. The role of women's leadership and gender equity in leadership and health system strengthening. Glob Health Epidemiol Genom 2017;2.

41 Downs JA, Mathad JS, Reif LK, et al. The ripple effect: why promoting female leadership in global health matters. Public Health Action 2016;6:210-1.

42 Beaman L, Duflo E, Pande R, et al. Female leadership raises aspirations and educational attainment for girls: a policy experiment in India. Science 2012;335:582-6.

43 Salway S, Jesmin S, Rahman S. Women's employment in urban Bangladesh: a challenge to gender identity? Dev Change 2005;36:317-49.

44 Alexander AC. Change in women's descriptive representation and the belief in women's ability to Govern: a virtuous cycle. Pol \& Gen 2012;8:437-64.

45 Ved R, Scott K, Gupta G, et al. How are gender inequalities facing India's one million ASHAs being addressed? policy origins and adaptations for the world's largest all-female community health worker programme. Hum Resour Health 2019;17:3.

46 Mahon T, Fernandes M. Menstrual hygiene in South Asia: a neglected issue for wash (water, sanitation and hygiene) programmes. Gend Dev 2010;18:99-113.

47 Pande R, Ford D. Gender quotas and female leadership. Washington, DC: World Bank, 2012

48 Burke RJ, Major DA. Gender in organizations: are men allies or Adversaries to women S career advancement? Edward Elgar Publishing, 2014. 